\title{
Experimental investigation for the effects of wire EDM process parameters over the tapered cross-sectional workpieces of titanium alloys (Ti6Al-4V)
}

\author{
Muhammad Wasif, Syed A. Iqbal, Anis Fatima, Saima Yaqoob, and Muhammad Tufail \\ Department of Industrial and Manufacturing Engineering, \\ NED University of Engineering and Technology, Karachi, 75270, Pakistan \\ Correspondence: Muhammad Wasif (wasif@neduet.edu.pk)
}

Received: 13 March 2020 - Revised: 14 April 2020 - Accepted: 12 May 2020 - Published: 17 June 2020

\begin{abstract}
The main purpose of this research is to examine the outcomes of process parameters of Wire Electrodischarge Machining over the tapered workpieces of Titanium Alloy (Ti6Al-4V). Taper angle, current and pulseoff time are considered as the controllable factors effecting the response variables. Each sample has been cut with varying sets of machine controllable parameters to assess their effect on response variables; kerf width, wire wear, Material Removal Rate and surface roughness. Analysis of variances is applied, and mean Reponses are determined to recognize and compare the most influencing parameters over the response variables for the WEDM Process. Regression model for the response variables are also developed using which optimized WEDM process parameters are determined for the optimal response variables. It can be concluded that varying thickness of materials due to tapered cross section affects all the four-response variable, while, current and pulse-off time along with their interactions have high impact over the response variables.
\end{abstract}

\section{Introduction}

Wire electro-discharge machining (WEDM), wire-cut or wire-cutting process is a variant of electro discharge machining $(\mathrm{EDM})$ that erodes the material using electrical discharge (sparks). In this process, a thin conductive wire electrode, moving between two spools, is fed to the thick material plates immersed into a dielectric medium (see Fig. 1) (El-Hofy, 2005).

During the WEDM process, electrode wire is winded from a fresh pool towards the other pool with a constant speed along the vertical direction while maintaining tension between the pools. The wire is fed perpendicular to the face of the workpiece where, the feed of the wire inside the workpiece is controlled thorough the movements of wire or table using the CNC contouring (see Fig. 1). In WEDM, the material of the electrode wire is usually copper, tungsten or brass (Asgar and Singholi, 2018). Ionized water is used as a dielectric medium during the WEDM process which shield the workpiece and tool. Rapid DC pulses are generated and repeated in thousands of time per second. At a certain volt-

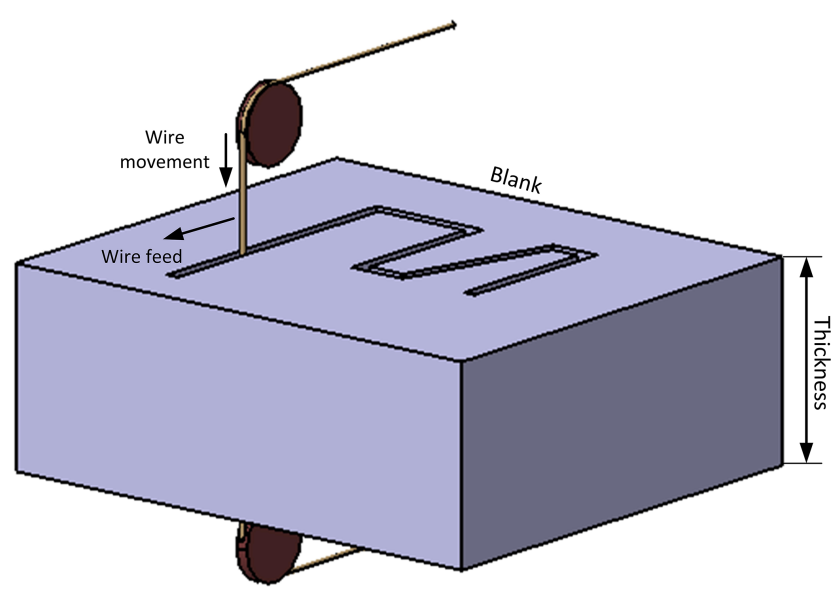

Figure 1. Illustration of Wire EDM Process. 
age fluid becomes ionized and sparks are generated between the winding wire the and workpiece material, erodes the materials from the workpiece. Deionized water is constantly sprayed on the workpiece with the help of nozzles to flush out the chips. Since the WEDM process is based on electrodischarge technique, hence the workpiece materials must be a conductor (Asghar, 2005). However, new researches also proposed WEDM of low conductive workpieces, such as polycrystalline diamond (PCD), ceramics and cermet (ElHofy, 2005).

There are number of parameters through which the WEDM process is controlled, amongst which core parameters are; material of workpiece, material of wire, dielectric medium, pulse on time, pulse off time, wire tension, wire feed, peak current, thickness of workpiece or length of wire exposed to workpiece (Jameson, 2001).

WEDM is used to cut plates as thick as $300 \mathrm{~mm}$, which are difficult to machine using the traditional machining methods (Jameson, 2001). After CNC machines application of wire Electric Discharge Machining (WEDM) are widespread as they are being used to manufacture parts which have complex silhouette and contours. Major applications of the WEMD is the precision tools manufacturing, where punches, die plates and other tool components are cut using this process. Complex and large thickness sheet metals and composites are cut using the WEDM process in the aerospace industry. Whereas, precision and micro cutting processes are also performed using the WEDM process in the industry. It is being utilized in advanced technologies such as medical and aeronautical domains that deal with great precision and accuracy (Ho et al., 2004). Researchers applied various techniques to study the effects of process parameters and optimize the outcome of the WEDM process. A comprehensive literature review is presented below.

Huang and Liau (2003) performed a research to analyse the impact of pulse on/off time, feed-rate, wire tension and dielectric pressure over the MRR and surface roughness of Inconel (SKD-11) while cutting it through the wire EDM. Gauri and Chakraborty (2009) applied Taguchi Method to study the effect of pulse-on time, wire tension, delay time, wire feed speed and ignition current intensity over the surface finish, MRR and wire wear of various materials. Raksiri and Chatchaikulsiri (2010) analysed and optimized the cutting thickness error by using feed rate and the servo voltage as process parameters for the WEDM of Inconel (SKD-11). Somashekhar et al. (2012) worked on the range of capacitance, gap voltage, and federate by using similar experimental setup and evaluated their influence over the MRR and surface roughness over Aluminium Alloy. Durairaja et al. (2013) observed the response of pulse on/off time and voltage on the kerf width and surface roughness of stainless steel (SS304) by utilizing the multi-objective grey relational grade methodology. Liao et al. (2014) developed analytical models after preforming experiments using wire of Inconel (SKD11) and discussed the effect of pulse on/off time on kerf width, spark frequency, and surface roughness. Welling (2014) and Klocke et al. (2014) optimized the WEDM process parameters for maximum MRR and minimum surface roughness for Inconel 718 and claims that these parameters are directly affected by the process input parameters. Mahapatra et al. (2006), Sandeep (2013) and Lodhi and Agarwal (2014) used the Taguchi method and Genetic algorithm to optimize the MRR and surface roughness by controlling the pulse frequency, discharge current, wire tension, wire speed and dielectric flow rate for the Tool Steel. Dongre et al. (2015) and Joshi et al. (2017) used almost same investigation as that of Gauri and Chakraborty (2009), to optimize of current, pulse-on time, workpiece geometry for the WEDM of silicon. They aim of the study is to retain higher MRR for the lower chip thickness for the chip manufacturing. Okada et al. (2015) analysed and optimized the wire breakage and kerf width during the wire EDM of SKD11 using the computational fluid dynamic (CFD) technique. Kamei et al. (2016) presented another trend in WEDM, which is frequency and vibration of wire during the WEDM of SKD-11. They determined the effects of wire deflection, wire tension and position of the work piece on the frequency and vibration of the wire by using a high-speed camera. Takayama et al. (2016) improved the productivity of WEDM process of SKD-11 by employing a closed loop system, by optimizing the surface finish, the cutting precision of workpiece and wire break frequency. Babu and Soni (2017) applied Taguchi method to optimize the process parameter for the optimal surface roughness during the WEDM of Inconel 625 material. Rajmohan and Kumar (2017) performed the multi-variable optimization of pulse-on/off time, wire speed, wire tension and current for the optimal values of kerf width, MRR and surface roughness of duplex stainless steel (DSS). Conde et al. (2018) used multivariable optimization technique by altering the height of work samples, dielectric pressure and pulse-off time for the WEDM of steel (D2) for improved wire lag and concavity effect.

Saini and Verma (2014) performed multi-variable optimization for the Titanium Alloy (Ti-6Al-4V), employing the Taguchi method to determine the effects of dielectric conductivity, pulse width, time between pulses, maximum feed rate, servo control mean voltage, wire feed over the material removal rate. Reddy et al. (2015) performed the analysis of kerf width in the research by replacing Titanium with Aluminium Alloy HE30. Majumder and Maity (2017) applied the multiresponse optimization for WEDM process parameters of $\mathrm{Ni}$ Ti shape memory alloy using Taguchi Method. They studied the response of pulse-on time, pulse-off time, wire feed, wire tension over the cutting speed, kerf width, surface roughness. Optimal process parameters are obtained for the favourable cutting speed, kerf width and surface roughness. Abhinesh et al. (2014) also worked for the titanium alloys and studied the results of MRR and wire wear by changing the wire material. Kumar and Singh (2018) extended the research by changing the speed capacitance and electrode ratio of the 
wire cut for the same Titanium Alloy. Magabe et al. (2019) applied Taguchi experimental design to evaluate the effects of spark gap voltage, pulse on time, pulse off time, wire feed rate during the WEDM of Nickel Titanium Alloy (Ni55.8Ti) over the material removal rate and surface finish.

Limited research have been conducted for the Titanium Alloy (Ti-6Al-4V), specially with diversified response variables. It was revealed that most of the researches are conducted on straight cross section surfaces with constant profiles. Almost no research has been performed on varying profile. Whereas, varying profile is considered important for machining intricate parts in car manufacturing, aeronautical applications, machine tools and medical tools. Due to the need of industry, tapered workpieces of Titanium alloy (Ti6Al-4V) with varying profile have been considered in this research. Hence the effect of taper angle has also been discussed over the outcomes of wire EDM of the Titanium alloy to address the industrial need. In most of the literate cited above, one or two response variables, such as surface finish with MRR or any other combinations are analysed using the experimental techniques. Whereas, four essential response variables (kerf width, surface roughness, wire wear and MRR) during the WEDM process are considered. The effects of core process parameters on these variables are analysed in this research. Dependency of response variables on each other are also discussed in detail. Using the experimental data, analytical models for the four response variables are developed, relating the process parameters with the variables, which can be further used to predict the four outcomes with the provided taper angle, current and pulse-off time. Process parameters are also optimized using the analytical models to obtain the favourable response outcomes.

\section{Experimental approach}

Main outcome of this research is to investigate the effect of WEDM process for the three types of tapered workpieces. To conduct the research and analysis, sequential methodology and components are discussed in detail.

CHMER CW-43CF CNC EDM wire cut has been used to carry out the experiments in this study. The configuration of the wire cut machine is such that it has maximum range of $500 \mathrm{~mm} \times 350 \mathrm{~mm} \times 200 \mathrm{~mm}$ along its $x, y$ and $z$ axis.

Titanium alloy (Ti6Al-4V) has been considered as a main material due to its hardness and ample applications in aerospace and tool manufacturing industry (see Table 1). This alloy has good strength to weight ratio when comparing with steels and nickel-based alloys (Peters et al., 2003). Pure Titanium and Ti-6Al-4V (grade 5) are widely used for implantation in human body as bones, due to its exceptional mechanical properties, thin layer of oxides, smaller elastic modulus and low density.

To conduct the WEDM experiments, three tapered workpieces each of angles 30,45 and $60^{\circ}$ are machined (see
Table 1. Applications, mechanical and physical properties of metal alloys

\begin{tabular}{ll}
\hline Physical Properties & Titanium - Ti6Al-4V \\
\hline Chemical composition $(\%)$ & $\mathrm{Al}(6.0)$, \\
& $\mathrm{V}(4.0)$, \\
& $\mathrm{C}(0.08)$, \\
& $\mathrm{N}(0.05)$, \\
& $\mathrm{O}(0.2)$, \\
& $\mathrm{H}(0.0125)$, \\
& $\mathrm{Fe}(0.3)$, \\
& $\mathrm{Ti}(\mathrm{remaining})$ \\
& 4429 \\
Density $\left(\mathrm{kg} \mathrm{m}{ }^{-3}\right)$ & 334 \\
Ultimess $(\mathrm{BHN})$ & 950 \\
Modulus of Elasticity $(\mathrm{GPa})$ & 113.8 \\
Poisson's Ratio & 0.34 \\
Shear Modulus $(\mathrm{GPa})$ & 44 \\
Specific Heat Capacity $\left(\mathrm{J}\left(\mathrm{g}{ }^{\circ} \mathrm{C}\right)^{-1}\right)$ & 0.526 \\
Thermal Conductivity $\left(\mathrm{W}(\mathrm{m} \mathrm{K})^{-1}\right)$ & 6.7 \\
Melting Point $\left({ }^{\circ} \mathrm{C}\right)$ & $1604-1660$ \\
\hline
\end{tabular}

Table 2. Controllable factors, levels, and values.

\begin{tabular}{lllrrr}
\hline \multirow{2}{*}{ Symbol } & Factor & Unit & \multicolumn{3}{c}{ Levels } \\
\cline { 4 - 6 } & & & 1 & 2 & 3 \\
\hline \multirow{2}{*}{ A } & Taper Angle (Angle) & Degree & 30 & 45 & 60 \\
$C$ & Current & Ampere & 5 & 10 & - \\
POT & Pulse-off time & Micro Second & 20 & 40 & - \\
\hline
\end{tabular}

Fig. 3). These three tapered workpieces are duplicated for the accuracy of results. Hence total six workpieces are prepared.

One set of three workpieces are cut with the current of $5 \mathrm{~A}$ at two different settings of pulse-off times of 20 and $40 \mu$ s, whereas replicated workpiece set are cut with the $10 \mathrm{~A}$ of current at the two pulse-off times. Each of the workpiece is grinded and finished up to the dimensions mentioned in the Fig. 2. Whereas, replicated workpieces are marked with numbers for the purpose of identification.

In this research; taper angle, current and pulse off time (POT) are selected as the controllable factors, since these parameters or factors are found to have significant influence over the response variables. Few parameters are set as constant to focus on the response of the three selected parameters and their interaction on four response variables; kerf width $(\mathrm{mm})$, surface roughness $(\mu \mathrm{m})$, material removal rate $\left(\mathrm{mm}^{3} \mathrm{~min}^{-1}\right)$, and wire wear (percentage). Hence controllable factors used in the research are shown in the Table 2 along with their levels and values.

Diameter of wire $(0.25 \mathrm{~mm})$ is not changed due to the limitation of machine is OEM recommendations. Pulse-on and pulse-off times are related with each other, since pulseoff time is taken as controllable parameters, hence pulse-on time is taken as $25 \mu \mathrm{s}$. Due to the change of taper angle in 
(a)

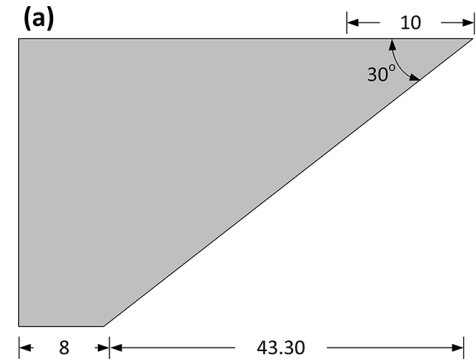

(b)

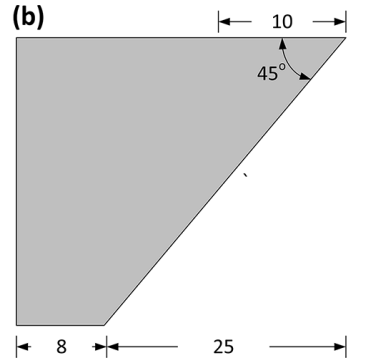

(c)

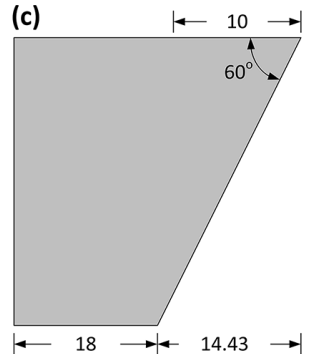

(d)

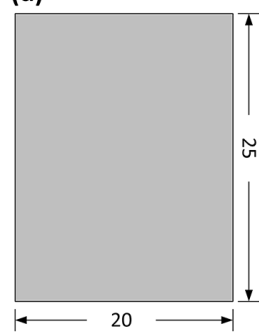

Figure 2. Dimensions (in mm) of tapered workpieces, (a) $30^{\circ}$ tapered workpiece, (b) $45^{\circ}$ tapered workpiece, (c) $60^{\circ}$ tapered workpiece, (d) side view of tapered workpieces.

(a)
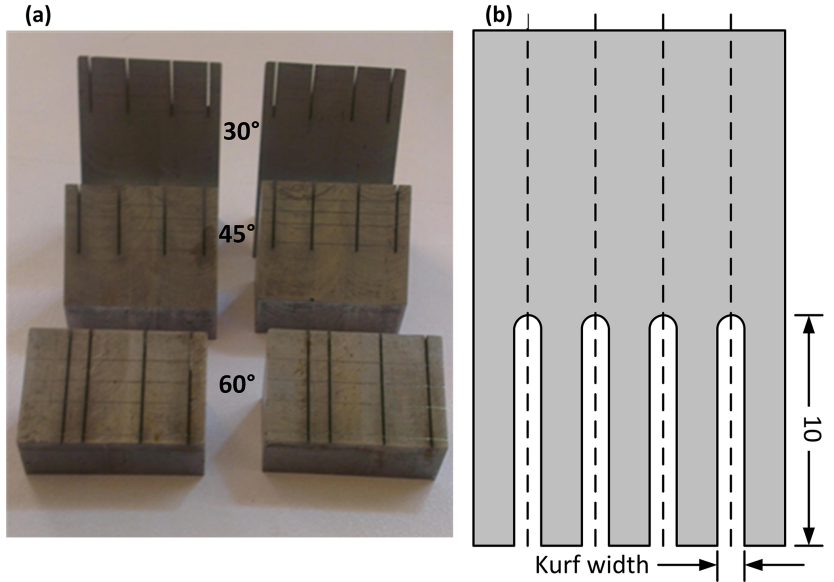

Figure 3. Titanium alloy workpieces cut with $30,45,60^{\circ}$ tapper angle. (a) Cut workpieces, (b) Dimensions of slots.

workpieces, feed rate is kept constant $20 \mathrm{~mm} \mathrm{~min}^{-1}$ to not change the relative velocity between the workpiece and the wire. Servo voltage $(65 \mathrm{~V})$, wire tension $(12 \mathrm{~N})$ and dielectric medium (ionized water) are also kept constant to limit the research. Flushing pressure is the discharge pressure of the dielectric flushing over the machining area to remove the eroded particles from the working zone, which is also kept at $2 \mathrm{Lh}^{-1}$.

Based on the controllable factors/parameters (shown in Table 2), total twelve experiments have been designed, which are replicated to eliminate the biasness in the results. Since the workpieces has been taken from same source, hence there is no need of blocking in the experiment. On each of the six blanks, four slots of $10 \mathrm{~mm}$ are generated through the WEDM. These four slots on each workpiece are generated by varying two levels of current (5 and $10 \mathrm{~A}$ ) and two levels of pulse-off time ( 20 and $40 \mu \mathrm{s}$ ). The response variables for the experiments are shown in Table 3, along with the units and measurements technique.

For each response variable, analysis of Variance (ANOVA) on the data is applied and the mean response variables are evaluated. Main hypothesis suggests that the mean response variables obtained by varying different factors or their inter-

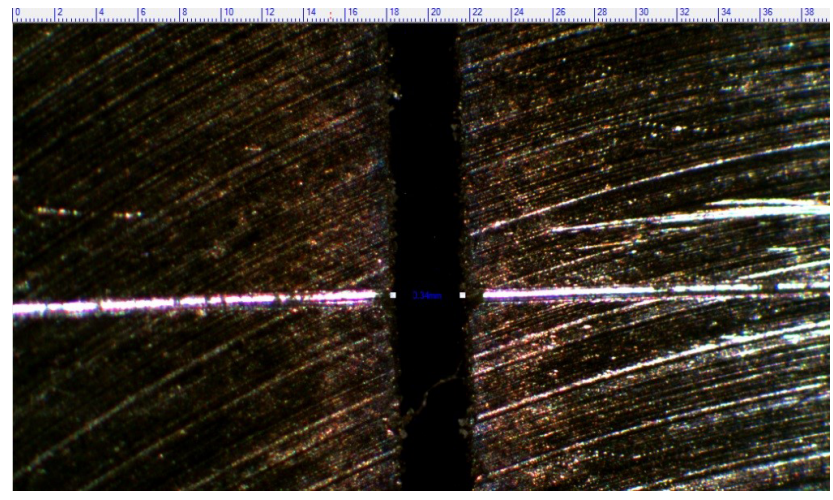

Figure 4. Kerf width of slot generated at $3 \mathrm{~mm}$ along the width at $45^{\circ}$ taper angle Titanium Alloy workpieces (Cut with pulse-off time of $20 \mu$ s and $10 \mathrm{~A}$ ).

actions are same to each other. That is, there is no influence of the factors or their interactions exists on the response variables. Whereas, alternate hypothesis suggest that the means of response variable are different for variations in the controllable factors or their interactions. Alternate hypothesis suggests that since the means are different, hence the factors or their interactions have significant influence over the response variable.

Firstly, analysis on kerf width is carried out, through microscopic photography on MM 500-T MTI corporation microscope, with digital camera DCM 310 attached to it. The snapshots were captured at different distances from the edge along the width of the workpiece i.e. at 3, 5, 7 and $10 \mathrm{~mm}$. Snapshots of kerf width of slots in Titanium Alloys at 45, 60 and $30^{\circ}$ tapered workpieces are taken. These photographs are further analysed through Scope Photo 3.0 and the kerf width are measured for all the workpieces. Each reading is taken twice; average readings are taken as a final reading and used for further analysis. Figure 4 shows an enlarge images of kerf width taken through the microscope.

The tapered blanks are cut along the width and the dotted lines shown in Fig. 3b, to separate the WEDM cut pieces for the analysis of surface roughness $\left(R_{a}\right)$. Surface roughness of the workpiece are analysed using the Meiji EMZ-8TR- 
Table 3. Response variable used in the research.

\begin{tabular}{llll}
\hline Symbol & Reponses Variable & Unit & Measuring Technique \\
\hline KW & Kerf Width & Mm & $\begin{array}{l}\text { Measured at four distance }(3,5,7 \text { and 10 mm) along the width of the workpieces } \\
\text { using stereo microscope. }\end{array}$ \\
SR & Surface Roughness & $\mu \mathrm{m}$ & $\begin{array}{l}\text { Measured using the roughness meter. } \\
\text { MRR }\end{array}$ \\
Material Removal Rate & $\mathrm{mm}^{3} \mathrm{~min}^{-1}$ & $\begin{array}{l}\text { Volume of material removed in unit time } \\
\text { Percentage }\end{array}$ & Ratio of loss in weight of wire after machining to weight of wire before machining \\
\hline
\end{tabular}

PBH Zoom Stereo Microscope with the magnification range of 10 to $45 \times$. Surface roughness with high precision of each slot is measured using the ConturoMatic T2 Surface roughness meter which can measure up to $250 \mathrm{~mm} \times 320 \mathrm{~mm}$ of workpiece with a resolution of $0.033 \mu \mathrm{m}$. Surface roughness $\left(R_{a}\right)$ on each slot of workpiece is measured at three places for studying the effect of varying thickness. Continuous surface roughness is measured at the $10 \%, 50 \%$ and $100 \%$ height of the WEDM slotted surface on each slot separately. Mean surface roughness in millimetres is determined by taking the mean of average surface roughness measured at the three heights of the WEDM slotted surface.

MRR is the change in mass of workpiece before and after the WEDM cutting per unit machining time. Following relationships is used to determine the MRR of the WEDM process;

$\mathrm{MRR}=\Delta m / \rho \cdot T_{\mathrm{m}}$

Where, $\Delta m$ is the change in mass of the workpiece, $\rho$ is the density of material and $T_{\mathrm{m}}$ be the WEDM machining time.

In order to assess the amount of wire utilized during cutting of each metal at various parameters and angles, the weight of wire before and after the WEDM cutting during each of the experiment is measured through an electronic physical balance having least count up to $0.0001 \mathrm{~kg}$.

\section{Analysis of reponses}

Experiments are conducted to measure the change in kerf width, surface roughness, MRR and wire wear with respect to the change in tapper angle, current and pulse-off time. Response variables measured for the controllable factors are input into the statistical analysis software Minitab and the design of experiment tool of the software has been used to evaluate the results.

\subsection{Analysis of kerf width}

Figure 5 presents the kerf width along the length of cut achieved through the WEDM with the different combinations of the process parameters. Highest kerf widths are seen in the workpieces with the taper angles of $30^{\circ}$. It is due to the least surface area of the Titanium alloy work piece exposed to the wire cut erosion. Due to high amount of current (5 and $10 \mathrm{~A}$ ), erosion intensity is high within the smaller exposed area with $30^{\circ}$ taper angle, causing the erosion of substantial number of particles within the region resulting in higher kerf widths. Kerf widths are also fluctuating along the length of the workpiece due to the pulse-off time frequency. Lower kerf widths are seen in the workpieces having the taper angles of 45 and $60^{\circ}$. Considering the same reason, the kerf width should decrease along the length of the workpiece due to the distribution of erosion, whereas, it slightly increases. It is due to the large exposed surface area to the erosion along the length, where the heat generated in the region cause the low surface finish and large kerf width due to lower thermal conductivity of Titanium alloy.

Table 4 shows the analysis of variance (ANOVA) results obtained through the experimental data. It shows that taper angle is the only significant factor influencing the kerf width with the $P$-value less than $5 \%$ for the $95 \%$ confidence inteval. Current and pulse-off time are not significant factors, whereas, the interaction of factors do not have significant impact over the kerf width in Titanium.

Figure 6 shows the variation of mean kerf width with the contraollable factors. It shows that the mean kerf width decreases with the increase in the taper angle. It is due to the increase in exposed surface in errosion zone and distribution of errosion intensity over it. ANOVA suggests that the effects of current and pulse-off time are insignificant ( $P$-values $>5 \%$ ). Referring to the Table 5, no significant impact of interactions of factors are seen.

\subsection{Analysis of surface roughness}

Table 5 presents the ANOVA for the surface roughness in Titanium Alloy workpiece, which shows that the only significant factor influencing the surface roughness is the interaction of taper angle and current $(P$-value $<0.05)$. Although minute but insignificant effect of taper angle and current individually is also present over the surface roughness of WEDM sample of Titanium (Ti6Al-4V).

Figures 7 and 8 show the effect of factors and their interactions over the surface roughness during the WEDM of titanium workpiece.

Figure 7 shows that the mean surface roughness has insignificant influence of process parameters as evident by the Table 5. Figure 8 shows that the interaction effect of taper 


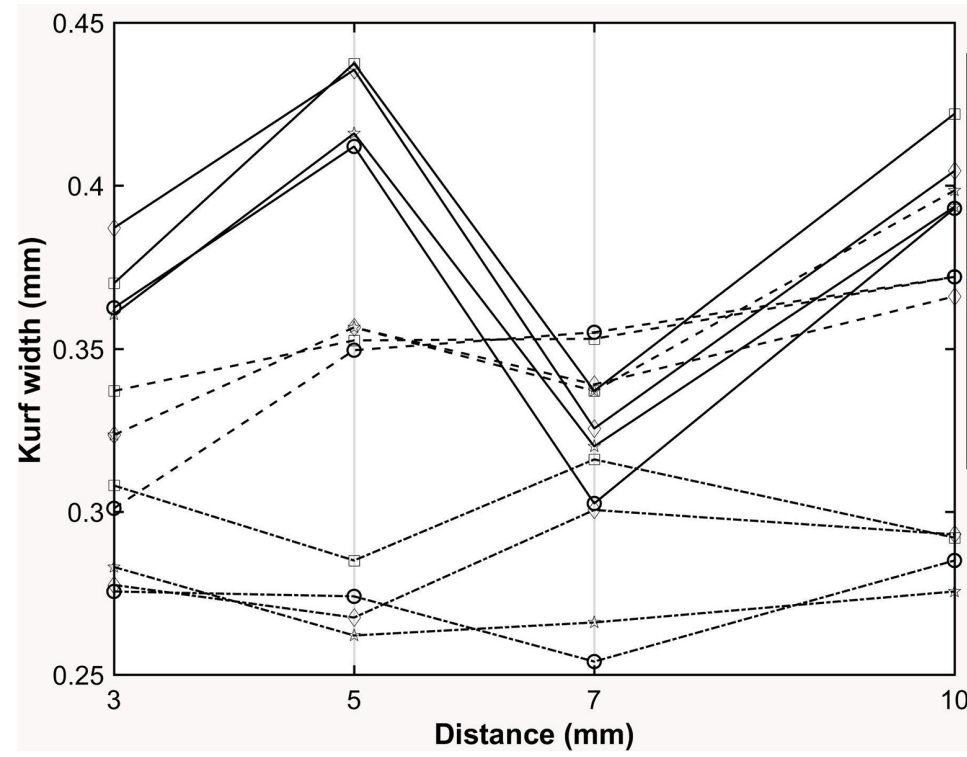

- - Angle $=30^{\circ}, \mathrm{l}=5 \mathrm{~A}, \mathrm{t}=20 \mu \mathrm{s}$ - Angle $=30^{\circ}, \mathrm{l}=5 \mathrm{~A}, \mathrm{t}=40 \mu \mathrm{s}$ $\neg$ Angle $=30^{\circ}, \mathrm{l}=10 \mathrm{~A}, \mathrm{t}=20 \mu \mathrm{s}$ $\square$ Angle $=30^{\circ}, \mathrm{l}=10 \mathrm{~A}, \mathrm{t}=40 \mu \mathrm{s}$ - 0 - Angle $=45^{\circ}, \mathrm{l}=5 \mathrm{~A}, \mathrm{t}=20 \mu \mathrm{s}$ $-\rightarrow>-$ Angle $=45^{\circ}, \mathrm{l}=5 \mathrm{~A}, \mathrm{t}=40 \mu \mathrm{s}$ $-\diamond-$ Angle $=45^{\circ}, \mathrm{l}=10 \mathrm{~A}, \mathrm{t}=20 \mu \mathrm{s}$ - $\boxminus-$ Angle $=45^{\circ}, \mathrm{l}=10 \mathrm{~A}, \mathrm{t}=40 \mu \mathrm{s}$ $-\Theta-$ Angle $=60^{\circ}, l=5 \mathrm{~A}, \mathrm{t}=20 \mu \mathrm{s}$ $\cdots$ - Angle $=60^{\circ}, \mathrm{l}=5 \mathrm{~A}, \mathrm{t}=40 \mu \mathrm{s}$ $-\rightarrow-$ Angle $=60^{\circ}, \mathrm{l}=10 \mathrm{~A}, \mathrm{t}=20 \mu \mathrm{s}$ $-\because--$ Angle $=60^{\circ}, \mathrm{l}=10 \mathrm{~A}, \mathrm{t}=40 \mu \mathrm{s}$

Figure 5. Effect of controllable factors over the kerf width along the length of workpiece.

Table 4. Analysis of variance for the kerf width.

\begin{tabular}{lrrrrr}
\hline Source & Degree of Freedom & Adjusted Sum of Squares & Mean Sum of Squares & $F$-Value & $P$-Value \\
\hline Taper Angle $(A)$ & 2 & 0.0430108 & 0.0215054 & 66.40 & 0.000 \\
Current $(C)$ & 1 & 0.0012768 & 0.0012768 & 3.94 & 0.070 \\
Pulse-off Time $($ POT $)$ & 1 & 0.0012262 & 0.0012262 & 3.79 & 0.075 \\
Angle $\times$ Current & 2 & 0.0003728 & 0.0001864 & 0.58 & 0.577 \\
Angle $\times$ POT & 2 & 0.0008424 & 0.0004212 & 1.30 & 0.308 \\
Current $\times$ POT & 1 & 0.0000509 & 0.0000509 & 0.16 & 0.699 \\
Angle $\times$ Current $\times$ POT & 2 & 0.0000859 & 0.0000429 & 0.13 & 0.877 \\
Error & 12 & 0.0038866 & 0.0003239 & & \\
\hline Total & 23 & & & &
\end{tabular}

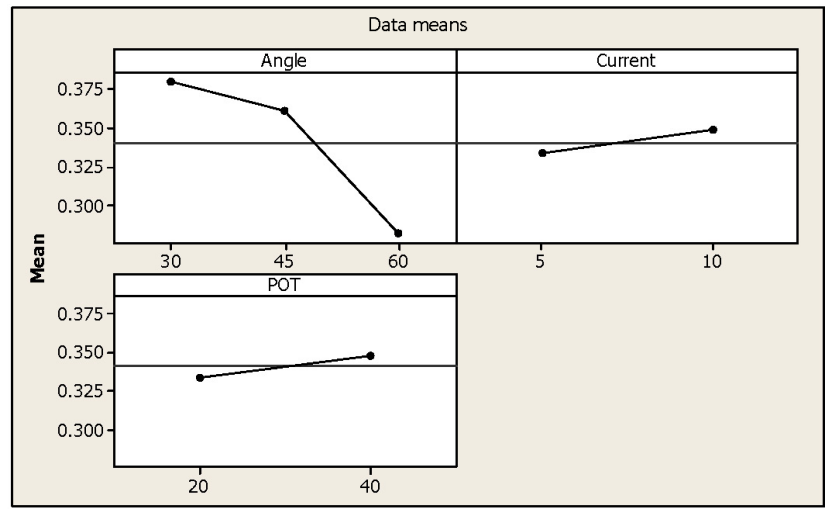

Figure 6. Main effect plots of mean kerf width.

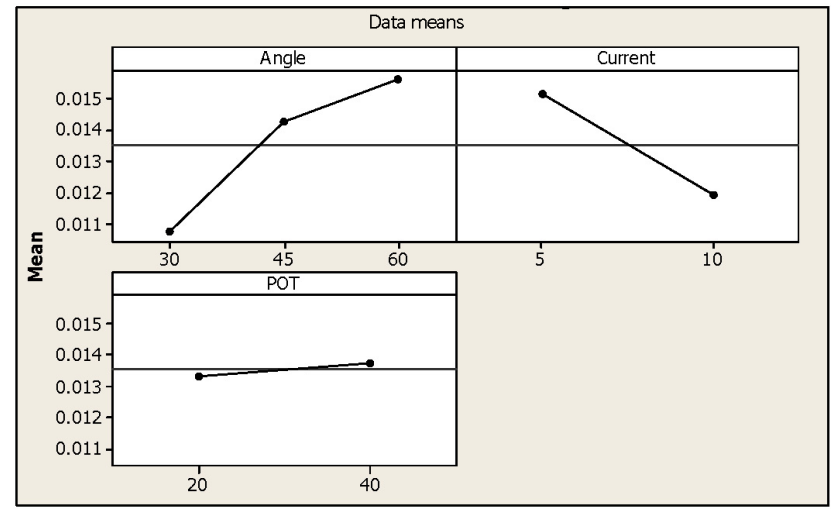

Figure 7. Main effect plots of mean surface roughness. 
Table 5. Analysis of variance for surface roughness.

\begin{tabular}{lrrrrr}
\hline Source & Degree of Freedom & Adjusted Sum of Squares & Mean Sum of Squares & $F$-Value & $P$-Value \\
\hline Taper Angle $(A)$ & 2 & 0.0001011 & 0.0000505 & 3.04 & 0.085 \\
Current $(C)$ & 1 & 0.0000634 & 0.0000634 & 3.81 & 0.075 \\
Pulse-off Time $($ POT $)$ & 1 & 0.0000010 & 0.0000010 & 0.06 & 0.807 \\
Angle $\times$ Current & 2 & 0.0001398 & 0.0000699 & 4.20 & 0.041 \\
Angle $\times$ POT & 2 & 0.0000303 & 0.0000152 & 0.91 & 0.428 \\
Current $\times$ POT & 1 & 0.0000150 & 0.0000150 & 0.90 & 0.360 \\
Angle $\times$ Current $\times$ POT & 2 & 0.0000333 & 0.0000167 & 1.00 & 0.396 \\
Error & 12 & 0.0001995 & 0.0000166 & & \\
\hline Total & 23 & & & & \\
\hline
\end{tabular}

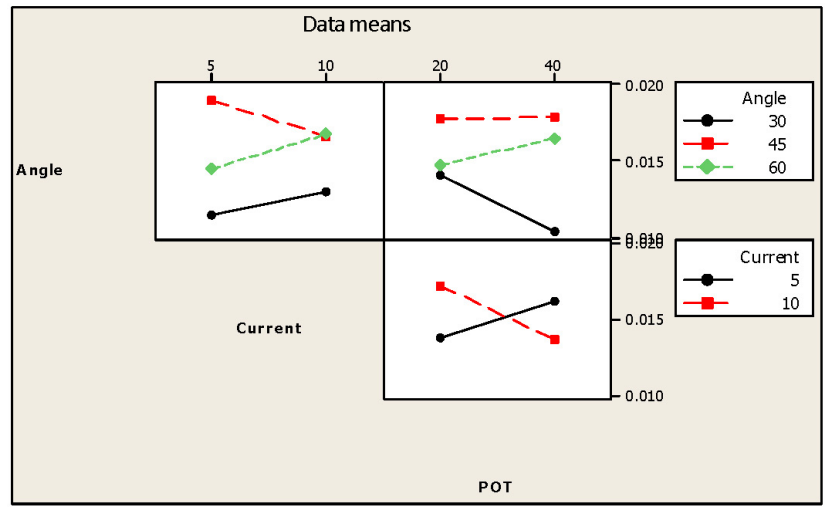

Figure 8. Interaction effect plots of mean surface roughness.

angle and current has significant influence, where mean surface roughness increases with the increase in current in 30 and $60^{\circ}$ taper workpiece, whereas, it decreases in $45^{\circ}$ taper workpiece. It may be due to the constant interaction of erosion area in case of $45^{\circ}$ taper workpiece, which is not present in case of other taper workpiece.

\subsection{Analysis of Material Removal Rate (MRR)}

In contrast to the result of ANOVA obtained for the MRR in Aluminium and Carbon Steel during the WEDM, the ANVOA for the Titanium workpiece is entirely different. Table 6 suggests that all the factors and their interactions have significant impact ( $P$-value $<0.05$ ) over the MRR of the workpiece. Influence of factors in order of increasing $F$-value are; current, pulse-off time, taper angle, angle with current, angle with current and pulse-off time and then current with pulseoff time.

Figure 9 shows that the MRR decreases with the taper angle due to the its low thermal conductivity, not forming a large kerf width and concentrating the heat in erosion zone. Influence of current is highest (see Table 6 and Fig. 9), that is increasing the current increases the MRR, whereas MRR decreases with increase in pulse-off time. It is due to the reason

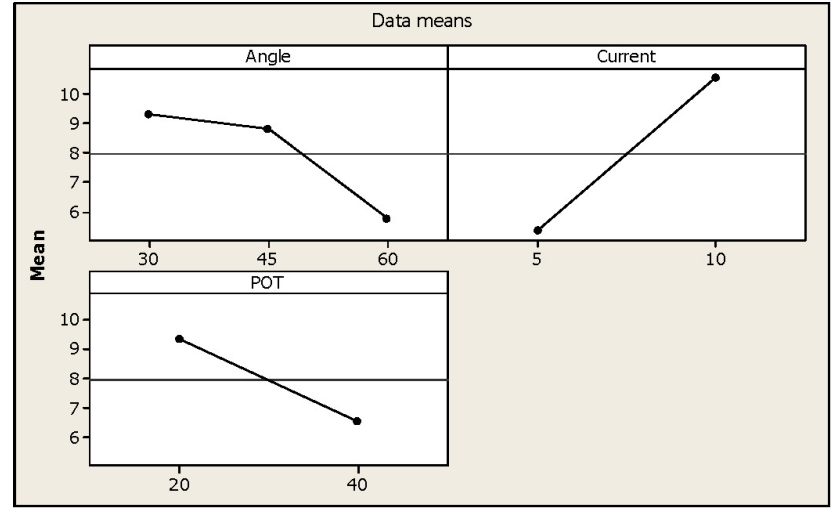

Figure 9. Main effect plots of Mean MRR.

that increasing current increases the rate of erosion whereas, pulse-off time, decreases the erosion rate. Figure 10 shows the effects of interactions of the factors, it shows that increasing current and decreasing the taper angle simultaneously increases the MRR due to the low erosion exposed area in low taper angle workpiece and high erosion rate due to high current. It can also be seen from the same figure that decreasing taper angle and increasing pulse-off time decreases the MRR due to low erosion rate. Whereas, with increased current and pulse-off time, the MRR decreases since it is drastically depending upon the pulse-off time in Titanium as suggested by the ANOVA $F$-value for POT is 118.8 .

\subsection{Analysis of wire wear}

It can be seen from Table 7 that the effect of taper angle, current, pulse-off time, interaction of taper angle with current and current with pulse-off time are significant to the wire wear in descending order.

Figures 11 and 12 show the variation in wire wear with respect to the main factors and their interactions, respectively. Figures 11 and 12 show that the wire wear increases with the increase in the taper angle and current and increase with the simultaneous increase of the both factors (see Fig. 12). It 
Table 6. Analysis of Variance for MRR.

\begin{tabular}{lrrrrr}
\hline Source & Degree of Freedom & Adjusted Sum of Squares & Mean Sum of Squares & $F$-Value & $P$-Value \\
\hline Taper Angle $(A)$ & 2 & 57.744 & 28.872 & 74.41 & 0.000 \\
Current $(C)$ & 1 & 160.627 & 160.627 & 414.00 & 0.000 \\
Pulse-off Time $($ POT) & 1 & 46.093 & 46.093 & 118.80 & 0.000 \\
Angle $\times$ Current & 2 & 24.816 & 12.408 & 31.98 & 0.000 \\
Angle $\times$ POT & 2 & 8.556 & 4.278 & 11.03 & 0.002 \\
Current $\times$ POT & 1 & 3.736 & 3.736 & 9.63 & 0.009 \\
Angle $\times$ Current $\times$ POT & 2 & 9.169 & 4.584 & 11.82 & 0.001 \\
Error & 12 & 4.656 & 0.388 & & \\
\hline Total & 23 & & & &
\end{tabular}

Table 7. Analysis of Variance for Wire Wear

\begin{tabular}{lrrrrr}
\hline Source & Degree of Freedom & Adjusted Sum of Squares & Mean Sum of Squares & $F$-Value & $P$-Value \\
\hline Taper Angle $(A)$ & 2 & 0.469039 & 0.234519 & 79.74 & 0.000 \\
Current $(C)$ & 1 & 0.081550 & 0.081550 & 27.73 & 0.000 \\
Pulse-off Time $($ POT) & 1 & 0.052697 & 0.052697 & 17.92 & 0.001 \\
Angle $\times$ Current & 2 & 0.091892 & 0.045946 & 15.62 & 0.000 \\
Angle $\times$ POT & 2 & 0.074858 & 0.037429 & 12.73 & 0.001 \\
Current $\times$ POT & 1 & 0.000014 & 0.000014 & 0.00 & 0.945 \\
Angle $\times$ Current $\times$ POT & 2 & 0.006872 & 0.003436 & 1.17 & 0.344 \\
Error & 12 & 0.035292 & 0.002941 & & \\
\hline Total & 23 & & & &
\end{tabular}

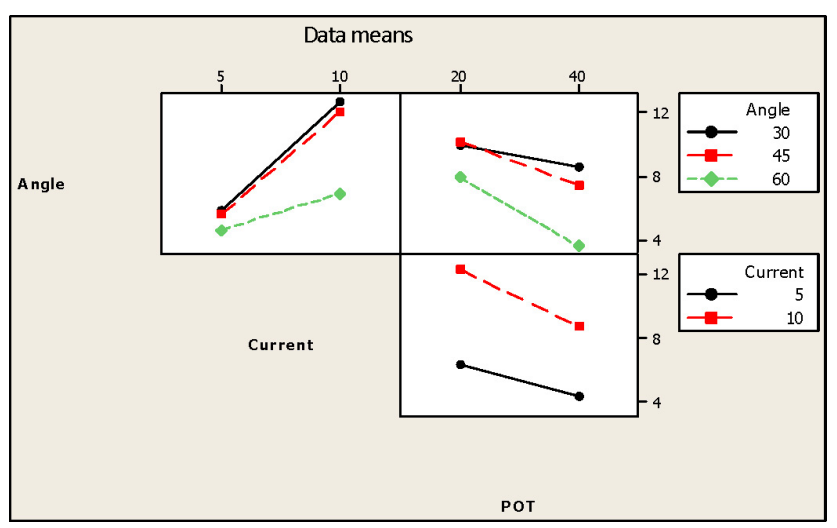

Figure 10. Interaction effect plots of Mean MRR.

is due the low thermal conductivity of Titanium causing the concentration of heat in erosion zone and cause high wire wear. It is also due to the high heat zone formed at the higher taper angle due to large exposed area to the erosion causing higher temperature in the region and high wear in the wire. The wire wear decreases with the increase in pulse-off time as shown in the Fig. 12.

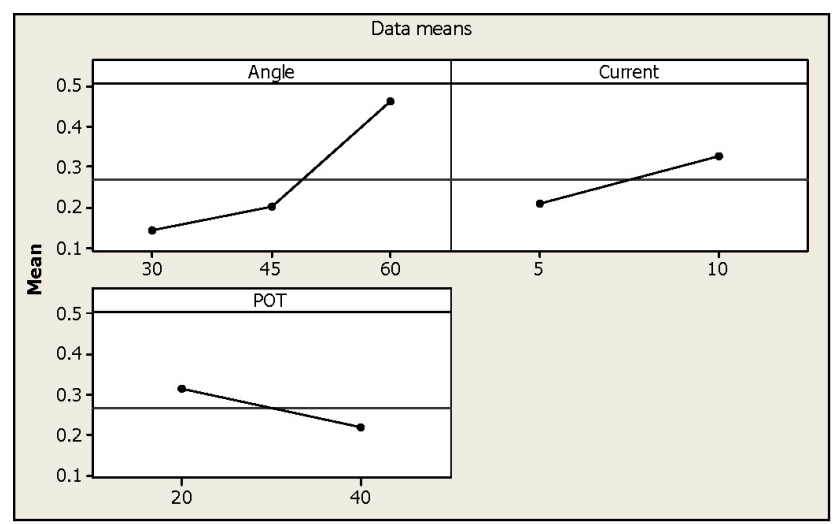

Figure 11. Main effect plots of mean wire wear.

Due to the lower thermal conductivity in Titanium (Table 1), the heat developed in the erosion region cause the titanium particle to erode rapidly as compared to the material having high thermal conductivity (Aluminium or carbon steel specially). Hence in Titanium, the erosion is effective due to concentrated heat and not conducting the heat generated by the EDM within the metal. Hence accumulated heat is dissipated during the higher pulse-off time and cause low wire wear. 


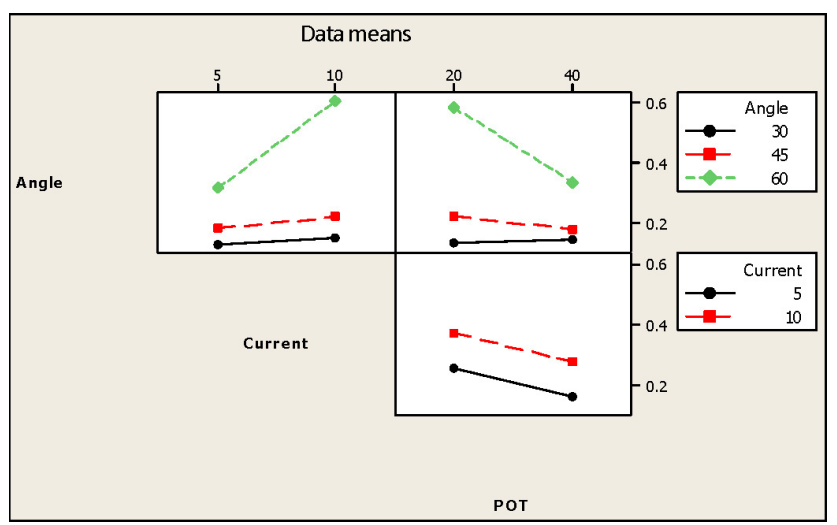

Figure 12. Interaction effect plots of mean wire wear.

\section{Regression models for the reponses variables}

Based on the response surface analysis of response variable, regression model of the kerf width, surface roughness, MRR and wire wear are developed. These regression models relate the response variables with the controllable factors. It can be used to predict the value of the response with the change of input factors. It is to be noted that the coefficients for each of the factors shows the weightage of the factors over the response variables. Following equations represent the regression models for the kerf width (KW), surface roughness (SR), MRR and wire wear (WW), respectively.

$$
\begin{aligned}
\mathrm{KW} & =0.2191+0.00842 A+0.00092 C \\
& +0.00004 \mathrm{POT}-0.000132 A^{2}+0.000058 C \cdot \mathrm{POT} \\
\mathrm{SR} & =0.0153+0.000125 A-0.00113 C \\
& -0.00008 \mathrm{POT}+0.000032 A \cdot C-0.000032 C \cdot \mathrm{POT} \\
\mathrm{MRR} & =-21.25+0.765 A+2.849 C \\
& +0.199 \mathrm{POT}-0.00569 A^{2}-0.0298 A \cdot C \\
& -0.00487 A \cdot \mathrm{POT}-0.01578 C \cdot \mathrm{POT} \\
\mathrm{WW} & =0.602-0.0297 A-0.0572 C \\
& +0.0148 \mathrm{POT}+0.00044 A^{2}+0.00181 A \cdot C \\
& -0.00043 A \cdot \mathrm{POT}-0.00003 C \cdot \mathrm{POT}
\end{aligned}
$$

Here, parameter $A$ denotes the taper angle, $C$ is used for current and POT for the pulse-off time. The $R^{2}$ values for the regression models presented in the Eqs. (2) to (5) are $89.8 \%$, $68.28 \%, 91.49 \%$ and $87.8 \%$.

Regression models have the effect of main factors, such as $A, C$ and POT, whereas, it also shows the effect of interaction of factors over the response variable, such as; $A \cdot C$, $A$. POT and $C$. POT. The other interaction of the factors having coefficient less than $10^{-5}$ are not significant and hence eliminated from the regression models. It can be seen from the Eqs. (2)-(5) that the lower coefficients $\left(10^{-4}\right)$ represent lower weightage of parameters over the response variables, which is also evident from ANOVA of the response variables.

\section{Optimization of process parameters}

Multi-objective optimization has been applied on the regression models presented in Eqs. (2) to (5). Response Surface Methodology (RSM) has been applied to optimize the process parameters; current $(C)$ and pulse-off time (POT) for each of the tapered workpiece. Following objective function has been defined for the optimal solution.

Optimal current and pulse-off time for the minimum kerf with, surface roughness and wire wear along with the maximum MRR of the three taper workpieces are presented in the Table 8 .

$$
\begin{aligned}
z & =\min [\mathrm{KW}(C, \mathrm{POT}) \quad \mathrm{SR}(C, \mathrm{POT}) \\
& -\operatorname{MRR}(C, \mathrm{POT}) \quad \mathrm{WW}(C, \mathrm{POT})]
\end{aligned}
$$

Here the negative sign with MRR shows that it is to be maximized. Objective function $z$, presents the multi-objective optimization keeping the taper angle constant for three types of workpieces. Using the RSM technique, following optimal values of current and pulse-off time are obtained having a composite desirability of $0.639,0.605$ and 0.523 for the three taper workpiece, respectively. Higher the composite desirability presents the better results but in case of multiobjective optimization, it is quite difficult since the composite response surface formed in RSM is not compatible for all the four outcomes. The optimal solutions are difficult to obtain complying with the minimization of all the four outcomes, hence in this case a composite desirability of 0.5 and may be taken as optimal results. Such similar condition has also been reported by Simon (2019) in multi-variable optimization using the Genetic Algorithm technique.

Based on the optimization of response variables, it can be seen from Table 8 that the optimal value of current is $10 \mathrm{~A}$ for the 30 and $45^{\circ}$ taper workpieces, whereas the optimal current value of $6.2121 \mathrm{~A}$ can be used for the $60^{\circ}$ taper workpiece. Value of optimal pulse-off time is $20 \mu$ s for all the tapered workpiece. It can also be noted that the most optimal response variables are obtained for the workpiece with $30^{\circ}$ tapper angle. Whereas, the least optimal values are obtained for the workpiece with $30^{\circ}$ tapper angle. Hence it can also be concluded from the optimization results that it is easier to control the response variable for the smaller tapper angle with the most optimal values, whereas, it varies with the increase in tapper angle. It is due to the reason that the area of erosion increases with the taper angle, which causes the high heat zone in the area with low thermal conductivity in the Titanium alloy, resulting in higher kerf width, surface roughness and wire wear. 
Table 8. Optimal factor values for the WEDM cut of titanium (Ti6Al-4V).

\begin{tabular}{lrrr}
\hline Factors & For $30^{\circ}$ Taper & For $45^{\circ}$ Taper & For $60^{\circ}$ Taper \\
\hline Current $(A)$ & 9.998 & 10 & 6.464 \\
Pulse-off Time $(\mu \mathrm{s})$ & 20 & 20 & 20 \\
\hline Optimal Response Variables & & & \\
\hline Kerf Width (Min) & 0.3792 & 0.3594 & 0.2716 \\
Surface Roughness (Min) & 0.0096 & 0.0132 & 0.0141 \\
MRR (Max) & 14.034 & 13.177 & 7.125 \\
Wire Wear (Min) & 0.1136 & 0.3079 & 0.5212 \\
\hline
\end{tabular}

\section{Conclusions}

In this research effect of change of taper angle of workpiece, current and pulse-off time over the response variables; kerf width, surface roughness, MRR and wire wear during the WEDM cutting of Titanium Alloy Ti6Al-4V has been analysed. From the analysis of data and results, it can be concluded that;

- Taper angle is only the significant factor influencing the kerf width, which decreases with the increase in taper angle due to high surface area exposed to the wire EDM and low thermal conductivity of the Titanium Alloy. Due to low thermal conductivity of the Titanium Alloy, the heat generated during the erosion concentrated within the region, causing the larger kerf width and hence melting of the material.

- There is no single significant factor which influences the surface roughness, whereas, interaction of taper angle and current is the significant factor. Increase in current and taper angle simultaneously increase the surface roughness within the erosion region in the workpiece with 30 and $60^{\circ}$ taper angle whereas it decreases in the $45^{\circ}$ taper angle.

- Material Removal Rate (MRR) is significantly influenced by taper angle, current and pulse-off time and their interactions. It decreases with the increase in taper angle and pulse-off time due to the higher erosion exposition area and distribution of erosion over the larger area. Whereas, it is increased with the increase of current due to higher erosion rate at higher current.

- Wire wear is also significantly influenced by all the main factors and most of the interaction factors. It increases with the increase in taper angle and current since the erosion is distributed along the larger length of wire, causing the erosion in wire in the high heat zone formed due to the low thermal conductivity of the Titanium alloy. It decreases with the increase in pulse-off time due to low erosion in the region.
Regression model for the four-response variable relating the taper angle, current and pulse-off time are also established, which is validated through the earlier researcher reported in the literature. The values for the response variables are evaluated from the previous researches and for the same process parameters, response variables are determined using the developed regression model. Based on the error between the response variable value, it can also be concluded that the regression models are accurate and robust in nature. Finally, optimal current and pulse-off time are determined using the optimization of regression models for the workpiece with three different tapered angles. Optimal results suggest that the current with more than $5 \mathrm{~A}$ and constant pulse-off time of $20 \mu$ s provide the optimal response variables. Furthermore, most optimal response variables are observed in the workpiece with the lowest tapered angle.

Based upon the above-mentioned results it can be concluded that the material properties, such as melting point and thermal conductivity also plays a key role in selecting the WEDM process parameter, which are also sensitive to the taper angle or exposed area to the erosion.

Data availability. Data is availible at Materials Cloud Repository with DOI: https://doi.org/10.24435/materialscloud:e7-rf (Wasif, 2020).

Author contributions. All authors contributed equally in the research work in designing, conducting, analysing and writing the manuscript. The sequence of authors name is based on their agreed upon order.

Competing interests. The authors declare that they have no conflict of interest.

Acknowledgements. We are thankful to Ali Zulqarnain and Muhammad Ali in Advanced Manufacturing Laboratory of Department of Industrial and Manufacturing Engineering for his consistent support and guidance. 
Financial support. This research has been supported by the NED University of Engineering and Technology (grant no. NED/ISP9996).

Review statement. This paper was edited by Peng Yan and reviewed by two anonymous referees.

\section{References}

Abinesh, P., Varatharajan, K., and Kumar, G. S.: Optimization of Process Parameters Influencing MRR, Surface Roughness and Electrode Wear During Machining of Titanium Alloys by WEDM, International Journal of Engineering Research and General Science, 2, 719-729, 2014.

Asgar, M. E. and Singholi, A. K. S.: Parameter study and optimization of WEDM process: A Review, in: 1st International Conference on Contemporary Research in Mechanical Engineering with Focus on Materials and Manufacturing (ICCRME-2018), 6-7 April 2018, Lucknow, India, 012007, https://doi.org/10.1088/1757-899X/404/1/012007, 2018.

Babu, T. V. and Soni, J. S.: Optimization of process parameters for surface roughness of Inconel 625 in Wire EDM by using Taguchi and ANOVA method, International Journal of Current Engineering and Technology, 7, 1127-1131, 2017.

Conde, A., Sanchez, J. A., Plaza, S., Ostolaza, M., de la Puerta, I., and Li, Z.: Experimental Measurement of Wire-lag Effect and Its Relation with Signal Classification on Wire EDM, Proc. CIRP, 68, 132-137, https://doi.org/10.1016/j.procir.2017.12.035, 2018.

Dongre, G., Zaware, S., Dabade, U., and Joshi, S. S.: Multiobjective optimization for silicon wafer slicing using wireEDM process, Mater. Sci. Semicond. Process, 39, 793-806, https://doi.org/10.1016/j.mssp.2015.06.050, 2015.

Durairaj, M., Sudharsun, D., and Swamynathan, N.: Analysis of Process Parameters in Wire EDM with Stainless Steel using Single Objective Taguchi Method and Multi Objective Grey Relational Grade, in: International Conference on Designl and Manufacturing, IConDM, Procedia Engineer., 64, 868-877, 2013.

El-Hofy, H. A.: Advanced Machining Processes: Non-traditional and Hybrid Machining Processes, McGraw-Hill, USA, ISBN 13978-0071453349, 2005.

Gauri, S. K. and Chakraborty, S.: Optimisation of multiple responses for WEDM processes using weighted principal components, Int. J. Adv. Manuf. Tech., 40, 1102-1110, https://doi.org/10.1007/s00170-008-1429-1, 2009.

Ho, K. H., Newman, S. T., Rahimifard, S., and Allen, R. D.: State of the art in wire electrical discharge machining (WEDM), Int. J. Mach. Tools. Manuf., 44, 1247-1259, 2004.

Huang, J. T. and Liao, Y. S.: Optimization of machining parameters of Wire-EDM based on Grey relational and statistical analyses, Int. J. Prod. Res., 41, 1707-1720, https://doi.org/10.1080/1352816031000074973, 2003.

Jameson, E.: Electrical Discharge Machining, Society of Manufacturing Engineers (SME), USA, ISBN 978-0872635210, 2001.

Joshi, K., Ananya, A., Bhandarkar, U., and Joshi, S. S.: Ultra thin silicon wafer slicing using wire-EDM for solar cell application, Mater. Design., 124, 158-170, https://doi.org/10.1016/j.matdes.2017.03.059, 2017.
Kamei, T., Okada, A., and Okamoto, Y.: High-speed Observation of Thin Wire Movement in Fine Wire EDM, Proc. CIRP, 42, 596600, https://doi.org/10.1016/j.procir.2016.02.266, 2016.

Klocke, F., Welling, D., Klink, A., Veselovac, D., Nöthe, T., and Perez, R.: Evaluation of Advanced Wire-EDM Capabilities for the Manufacture of Fir Tree Slots in Inconel 718, Proc. CIRP, 14, 430-435, https://doi.org/10.1016/j.procir.2014.03.039, 2014.

Kumar, R. and Singh, I.: Productivity improvement of micro EDM process by improvised tool, Precision Engineering, 51, 529-535, https://doi.org/10.1016/j.precisioneng.2017.10.008, 2018.

Liao, Y. S. and Yu, Y. P.: Study of specific discharge energy in WEDM and its application, Int. J. Mach. Tool. Manu., 44, 13731380, https://doi.org/10.1016/j.ijmachtools.2004.04.008, 2014.

Lodhi, B. K. and Agarwal, S.: Optimization of machining parameters in WEDM of AISI D3 Steel using Taguchi Technique, in: Proc. 6th CIRP International Conference on High Performance Cutting, Proc. CIRP, 14, 194-199, 2014.

Magabe, R., Sharma, N., Gupta, K., and Dawim, J. P.: Modeling and optimization of Wire-EDM parameters for machining of Ni55.8Ti shape memory alloy using hybrid approach of Taguchi and NSGA-II, Int. J. Adv. Manuf. Tech., 102, 17031717, https://doi.org/10.1007/s00170-019-03287-z, 2019.

Mahapatra, S. S. and Patnaik, A.: Parametric optimization of wire electrical discharge machining (WEDM) process using taguchi method, J. Braz. Soc. Mech. Sci., XXVIII, 423-429, 2006.

Majumder, H. and Maity, K.: Multi-Response Optimization of WEDM Process Parameters Using Taguchi Based Desirability Function Analysis, Proc. IOP Conf. Series: Materials Science and Engineering, 338, 012004, https://doi.org/10.1088/1757899X/338/1/012004, 2017.

Okada, A., Konishi, T., Okamoto, Y., and Kurihara, H.: Wire breakage and deflection caused by nozzle jet flushing in wire EDM, CIRP Annals, 64, 233-236, https://doi.org/10.1016/j.cirp.2015.04.034, 2015.

Peters, M., Kumpfert, J., Ward, C. H., and Leyens, C.: Titanium alloys for aerospace applications, Adv. Eng. Mater., 5, 419-427, 2003.

Rajmohan, K. and Kumar, A. S.: Experimental investigation and prediction of optimum process parameters of micro-wire-cut EDM of 2205 DSS, Int. J. Adv. Manuf. Technol., 93, 187-201, https://doi.org/10.1007/s00170-016-8615-3, 2017.

Raksiri, C. and Chatchaikulsiri, P.: CNC Wire-Cut Parameter Optimized Determination of the Stair Shape Workpiece, International Journal of Mechanical and Mechatronics Engineering , 4, 924 929, 2010.

Reddy, V. C., Deepthi, N., and Jayakrishna, N.: Multiple Response Optimization of Wire EDM on Aluminium HE30 by using Grey Relational Analysis, Mater. Today-Proc., 2, 2548-2554, https://doi.org/10.1016/j.matpr.2015.07.201, 2015.

Saini, P. K. and Verma, M.: Experimental Investigation of WireEDM Process Parameters on MRR of Ti-6al-4v Alloy, International Journal of Innovative Technology and Exploring Engineering (IJITEE), 4, 16-20, 2014.

Sandeep, K.: Research Trends in Electrical Discharge Machining: A Review, Res. J. Eng. Sci., 2, 56-60, 2013.

Simon, V.: Multi-objective optimization of hypoid gears to improve operating haracteristics, Mech. Mach. Theory, 146, 103727, https://doi.org/10.1016/j.mechmachtheory.2019.103727, 2019. 
Somashekhar, K. P., Mathew, J., and Ramachandran, N.: A feasibility approach by simulated annealing on optimization of microwire electric discharge machining parameters, Int. J. Adv. Manuf. Tech., 61, 1209-1213, 2012.

Takayama, Y., Makino, Y., Niu., Y., and Uchida, H.: The Latest Technology of Wire-cut EDM, Proc. CIRP, 42, 623-626, https://doi.org/10.1016/j.procir.2016.02.259, 2016.
Wasif, M.: Effects of Wire EDM Process Parameters over the Titanium Alloys (Ti6Al-4V), Materials Cloud Archive 2020.X, https://doi.org/10.24435/materialscloud:e7-rf, 2020.

Welling, D.: Results of Surface Integrity and Fatigue Study of WireEDM Compared to Broaching and Grinding for Demanding Jet Engine Components Made of Inconel 718, Proc. CIRP, 13, 339344, https://doi.org/10.1016/j.procir.2014.04.057, 2014. 